\title{
絶対節点座標アプローチにより定式化された梁要素による 骨組構造物のモデル化に関する研究*
}

\author{
高橋義 考*1, 清 水 信 行*1, 鈴木 浩 平*2
}

\author{
Study on the Frame Structure Modeling of the Beam Element \\ Formulated by Absolute Nodal Coordinate Approach
}

\author{
Yoshitaka TAKAHASHI*3, Nobuyuki SHIMIZU and Kohei SUZUKI \\ ${ }^{* 3}$ Department of Mechanical Engineering, Iwaki Meisei University, \\ 5-5 1 Iino, Chuohdai, Iwaki-shi, Fukushima, 970-8551 Japan
}

\begin{abstract}
Accurate seismic analysis of large deformable moving structures is still unsolved problems in the field of earthquake engineering. In order to analyze these problems, the nonlinear finite element method formulated by the absolute nodal coordinate approach is noticed. Because, this formulation has several advantages on mass matrix, elastic forces and damping forces in the case of large displacement problems. But, it has not been fully studied to build a frame structure model by using the beam element in the absolute nodal coordinate formulation. In this paper, we propose the connecting method of the beam element formulated by the absolute nodal coordinate. The coordinate transformation matrix of this element is introduced into the frame structure. This beam element has the characteristic that the mass matrix and bending stiffness matrix are constant even if in the case of large displacement problems, and this characteristic is being kept after the transformation. In order to verify the proposed method, we show the numerical simulation results of frame structures for a static problem and a vibration problem.
\end{abstract}

Key Words: Finite Element Method, Beam, Absolute Nodal Coordinate Approach, Frame Structure, Seismic Analysis

\section{1. 緒言}

大変位, 大回転を有する柔軟梁要素について，さま ざまな定式化が報告されており ${ }^{(1) \sim(6)}$, 近年, 絶対節 点座標アプローチによる定式化が Shabana らによっ て発表された (7) (8).この方法では, 節点座標として微 小または有限回転のかわりに勾配を用いている点が従 来の方法と異なる．著者らは弾性力に注目し, 要素座 標系に依存しない定式化を提案した。これにより大変 位問題においても回転変換行列を用いない曲げ剛性行 列を導出することができ, 構造解析に用いられるレー レー隇衰を導入できるようになった ${ }^{(9) \sim(11)}$.この他に も絶対節点座標アプローチによる柔軟要素の開発が盛 んに行われているが，この手法はまだ完成されたもの ではなく, 現在発展途上にある. そのため理論的な定

* 原稿受付 2004 年 2 月 17 日.

*1 正員, いわき明星大学理工学部機械工学科(-3970-8551 い わき市中央台飯野 5-5-1).

*2 正員, 東京都立大学工学研究科機械工学専攻(匹192-0397 八王子市南大沢 1-1).

E-mail : yositaka@iwakimu.ac.jp
式化に関する研究が多く, 具体的な構造物の解析への 適用例は少ない. 適用例としては曄道らの研究が存在 し, 鉄道車両のレールのモデル化に利用することで良 好な結果を得ている(12). しかし, 梁要素を直線的に結 合したモデルであり，骨組み構造物のモデル化を行っ た研究は見当たらない. 線形有限要素法と違い絶対節 点座標アプローチでは角度の代わりに勾配を節点座標 として用いる. そのため, 行列の重ね合わせで要素を 結合するために, 線形有限要素法の座標変換行列をそ のまま用いることはできない. 拘束条件式を用いて微 分代数方程式として骨組構造物をモデル化することは 可能であるが, 絶対節点座標アプローチ用の座標変換 行列を新たに定義し, 線形有限要素法のように行列の 重ね合わせで要素を結合することが出来れば骨組み構 造物のモデル化に便利である. 絶対節点座標で定式化 された梁要素を用いた骨組構造物のモデル化について は報告例がなく，また，実験による検証もおこなわれ ていないようである.

本研究では絶対節点座標アプローチで定式化された 
梁要素を実際の設計問題へ適用するために,この梁要 素による骨組構造物のモデル化手法について述べる. 拘束条件式を用いて微分代数方程式として骨組棈造物 をモデル化するのではなく，絶对節点座標アプローチ 用の座標変換行列を提案し, 従来の有限要素法と同じ ように行列の重ね合わせで梁要素を結合する方法を提 案する. 骨組み構造物の運動方程式は常微分方程式で 記述され, 大変位問題においても質量行列, 曲げ剛性 行列は定数行列で表すことができる.解析は微小变形 範囲に限定されるが, 大变位, 大回転を扱うことがで きるため, 運動を伴い, 時間と共に姿勢の変化する柔軟 構造物のモデル化にも応用が考えられる.モデル化を 検証するためにシミュレーションを行い, 従来の有限 要素法との比較と実験による検証についても述べる.

\section{2. 絶対節点座標アプローチによる梁要素の定式化}

梁要素と全体座標系 $O-X Y$ を図 1 に示す. 変形 していない状態の梁の長さを $l$, 断面積を $A$, 密度を $\rho$ とする. 図心軸上の任意点 $\mathrm{P}$ の位置ベクトル $\mathbf{r}$ は次式 で表すことができる.

$$
\mathbf{r}=\mathbf{S e} .
$$

ここで, $\mathbf{S}$ は形状関数, $\mathbf{e}$ は節点座標べクトルである. この節点座標べクトルは次式で表される.

$$
\mathbf{e}=\left[\begin{array}{llllllll}
e_{1} & e_{2} & e_{3} & e_{4} & e_{5} & e_{6} & e_{7} & e_{8}
\end{array}\right]^{T},
$$

ここで, $e_{1}, e_{2}$ は節点 $\mathrm{A} の X, Y$ 座標, $e_{5}, e_{6}$ は節点 $\mathrm{B}$ の $X, Y$ 座標である. また, $e_{3}, e_{4}$ と $e_{7}, e_{8}$ はそれぞれ 節点 $\mathrm{A}$ と Bにおける全体座標系から見た勾配を表し ており, 位置べクトルの $X$ または $Y$ 座標による偏微 分で定義される.

梁要素をベルヌーイ・オイラー梁とし, アイソパラ メトリック要素の考え方を導入すると, 形状関数は次

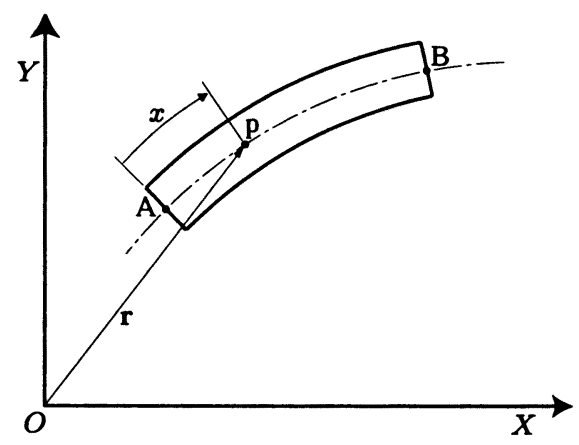

Fig. 1 Deformation of beam
式となる.

$$
\mathbf{S}=\left[\begin{array}{c}
\mathbf{S}_{1} \\
\mathbf{S}_{2}
\end{array}\right]=\left[\begin{array}{cc}
1-3 \xi^{2}+2 \xi^{3} & 0 \\
0 & 1-3 \xi^{2}+2 \xi^{3} \\
l\left(\xi-2 \xi^{2}+\xi^{3}\right) & 0 \\
0 & l\left(\xi-2 \xi^{2}+\xi^{3}\right) \\
3 \xi^{2}-2 \xi^{3} & 0 \\
0 & 3 \xi^{2}-2 \xi^{3} \\
l\left(\xi^{3}-\xi^{2}\right) & 0 \\
0 & l\left(\xi^{3}-\xi^{2}\right)
\end{array}\right]^{T}
$$

ここで, $\xi=x / l$ である.

梁要素の運動エネルギは次式で与えられる.

$$
T=\frac{1}{2} \int_{0}^{l} \rho \dot{\mathbf{r}}^{T} \dot{\mathbf{r}} d x,
$$

ここで $\dot{\mathbf{r}}$ は任意点 $\mathrm{P}$ の全体座標から見た速度べクトル であり，

$$
\dot{\mathbf{r}}=\mathbf{S} \dot{\mathbf{e}} .
$$

となる. 式 (5)を式 (4) に代入し整理することで, この 梁要素の質量行列 $\mathbf{M}$ は次式で表すことができる ${ }^{(10)}$.

$\mathbf{M}=A \rho l\left[\begin{array}{cccccccc}\frac{13}{35} & 0 & \frac{11 l}{210} & 0 & \frac{9}{70} & 0 & -\frac{13 l}{420} & 0 \\ 0 & \frac{13}{35} & 0 & \frac{11 l}{210} & 0 & \frac{9}{70} & 0 & -\frac{13 l}{420} \\ \frac{11 l}{210} & 0 & \frac{l^{2}}{105} & 0 & \frac{13 l}{420} & 0 & -\frac{l^{2}}{140} & 0 \\ 0 & \frac{11 l}{210} & 0 & \frac{l^{2}}{105} & 0 & \frac{13 l}{420} & 0 & -\frac{l^{2}}{140} \\ \frac{9}{70} & 0 & \frac{13 l}{420} & 0 & \frac{13}{35} & 0 & -\frac{11 l}{210} & 0 \\ 0 & \frac{9}{70} & 0 & \frac{13 l}{420} & 0 & \frac{13}{35} & 0 & -\frac{11 l}{210} \\ -\frac{13 l}{420} & 0 & -\frac{l^{2}}{140} & 0 & -\frac{11 l}{210} & 0 & \frac{l^{2}}{105} & 0 \\ 0 & -\frac{13 l}{420} & 0 & -\frac{l^{2}}{140} & 0 & -\frac{11 l}{210} & 0 & \frac{l^{2}}{105}\end{array}\right]$

次に弾性力の導出について述べる. 梁の軸方向の歪 エネルギ $U_{l}$ を次式で定義する.

$$
U_{l}=\frac{1}{2} \int_{0}^{l} E A \varepsilon^{2} d x .
$$

ここで, $E$ は弾性俰数, $\varepsilon$ は軸方向の歪を表す. 梁要素 の変形量が微小であり,変形している梁の長さが図 1 の点 $\mathrm{AB}$ 間の距離で近似できると仮定すると, 軸方向 の歪は次式で表すことができる.

$$
\begin{aligned}
\varepsilon & =\frac{l_{d}-l}{l} \\
& =\frac{\sqrt{\left(e_{5}-e_{1}\right)^{2}+\left(e_{6}-e_{2}\right)^{2}}-l}{l} .
\end{aligned}
$$

ここで, $l_{d}$ は変形している梁の長さを表す. 式 (8)を 式 (7) に代入すると, 軸方向の歪エネルギが得られ, 梁 要素の軸方向の変形に対する弾性力ベクトルが次式の ように導出できる(10). 


$$
\mathbf{F}_{l}=\mathbf{K}_{l} \mathbf{e}
$$

ここで,

$$
\mathbf{K}_{l}=\frac{E A \varepsilon}{l_{d}}\left[\begin{array}{cccccccc}
1 & 0 & 0 & 0 & -1 & 0 & 0 & 0 \\
0 & 1 & 0 & 0 & 0 & -1 & 0 & 0 \\
0 & 0 & 0 & 0 & 0 & 0 & 0 & 0 \\
0 & 0 & 0 & 0 & 0 & 0 & 0 & 0 \\
-1 & 0 & 0 & 0 & 1 & 0 & 0 & 0 \\
0 & -1 & 0 & 0 & 0 & 1 & 0 & 0 \\
0 & 0 & 0 & 0 & 0 & 0 & 0 & 0 \\
0 & 0 & 0 & 0 & 0 & 0 & 0 & 0
\end{array}\right]
$$

となる.

次に, 梁の曲げ変形に対する弾性力について述べる. 梁要素の曲げ変形による歪エネルギは次式で定義さ れる.

$$
U_{t}=\frac{1}{2} \int_{0}^{l} E I \kappa^{2} d x
$$

ここで, $I$ は断面二次モーメント, $\kappa$ は曲率を表してい る. 曲率について次の近似式が成り立つことが分かっ ている(10).

$$
\kappa^{2}=\left(\frac{\partial^{2} \mathbf{S}}{\partial x^{2}} \mathbf{e}\right)^{T}\left(\frac{\partial^{2} \mathbf{S}}{\partial x^{2}} \mathbf{e}\right) .
$$

式 (12) を式 (11) に代入し整理することで曲げ变形に 対する弾性力を次式のように表すことができる(10).

$$
\mathbf{F}_{t}=\left(\frac{\partial U_{t}}{\partial \mathbf{e}}\right)^{T}=\mathbf{K}_{t} \mathbf{e}
$$

ここで,

$$
\begin{aligned}
\mathbf{K}_{t} & =\int_{0}^{l} E I\left(\frac{\partial^{2} \mathbf{S}}{\partial x^{2}}\right)^{T}\left(\frac{\partial^{2} \mathbf{S}}{\partial x^{2}}\right) d x \\
& =\frac{E I}{l^{3}}\left[\begin{array}{cccccccc}
12 & 0 & 6 l & 0 & -12 & 0 & 6 l & 0 \\
0 & 12 & 0 & 6 l & 0 & -12 & 0 & 6 l \\
6 l & 0 & 4 l^{2} & 0 & -6 l & 0 & 2 l^{2} & 0 \\
0 & 6 l & 0 & 4 l^{2} & 0 & -6 l & 0 & 2 l^{2} \\
-12 & 0 & -6 l & 0 & 12 & 0 & -6 l & 0 \\
0 & -12 & 0 & -6 l & 0 & 12 & 0 & -6 l \\
6 l & 0 & 2 l^{2} & 0 & -6 l & 0 & 4 l^{2} & 0 \\
0 & 6 l & 0 & 2 l^{2} & 0 & -6 l & 0 & 4 l^{2}
\end{array}\right],
\end{aligned}
$$

である.この曲げ剛性行列は線形有限要素法の剛性行 列と同様に, 対称な定数行列である. 結果として, 梁要 素の弾性カベクトルは軸方向の変形と曲げ変形による 弾性力を合わせて次式となる.

$$
\mathbf{F}_{e}=\mathbf{F}_{l}+\mathbf{F}_{t} .
$$

式 (6), (16)により, 隇衰の無い場合の運動方程式は 次式となる.

$$
\mathbf{M e}+\mathbf{F}_{\boldsymbol{e}}=\mathbf{Q} .
$$

ここで, $\mathrm{Q}$ は外力ベクトルを表している、レーレー隇 衰を含む場合, 運動方程式は次式となる.

$$
\mathbf{M e ̈}+\mathbf{F}_{d}+\mathbf{F}_{e}=\mathbf{Q},
$$

ここで,

$$
\mathbf{F}_{d}=\left(\alpha \mathbf{M}+\beta \mathbf{K}_{t}\right) \dot{\mathbf{e}}
$$

である(11).

\section{3. 骨組樓造物のモデル化}

$3 \cdot 1$ 直線的な要秦の連結 図 2 に示すように梁 要素を直線的に結合することを考える。この例題では， 要素 1 の $\mathrm{Q}$ 点と要素 2 の $\mathrm{P}$ 点が結合するものとする. $\mathrm{P}$ 点と $\mathrm{Q}$ 点の節点座標は共通な座標となるので, 従来 の FEM と同様に行列の重ね合わせにより，梁要素を 結合することができる. 結合する前の要素 1 と要素 2 の運動方程式は次式となる。

$$
\begin{aligned}
& \mathbf{M}^{(1)} \ddot{\mathbf{e}}^{(1)}=\mathbf{Q}^{(1)}-\left(\mathbf{K}_{l}^{(1)}+\mathbf{K}_{t}^{(1)}\right) \mathbf{e}^{(1)}, \\
& \mathbf{M}^{(2)} \ddot{\mathbf{e}}^{(2)}=\mathbf{Q}^{(2)}-\left(\mathbf{K}_{l}^{(2)}+\mathbf{K}_{t}^{(2)}\right) \mathbf{e}^{(2)} .
\end{aligned}
$$

ここで添字 (1), (2) は要素番号を表している. 有限要 素法と同样に結合する節点部分の質量行列, 剛性行列, 節点座標ベクトル, 外カベクトルを重ねあわせること で，2つの要素を一つの連続体として結合することが できる.記述を簡単にするために, 8 行 8 列の質量行 列, 剛性行列を 2 行 2 列の行列で整理し，それに対応 して節点座標ベクトル, 外カベクトルも 2 行 1 列のヘ
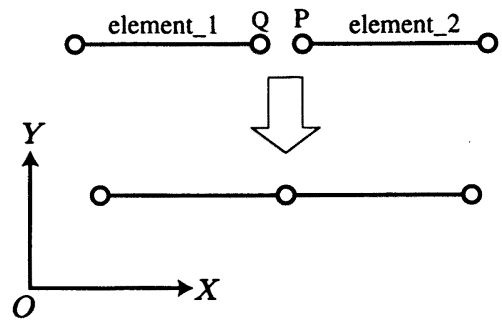

Fig. 2 Joint at straight part 
クトルで以下のように表すことにする.

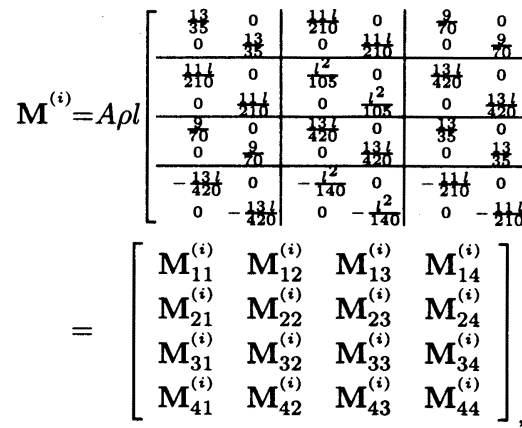

$$
\mathbf{K}^{(i)}=\mathbf{K}_{t}^{(i)}+\mathbf{K}_{l}^{(i)}
$$$$
=\left[\begin{array}{llll}
\mathbf{K}_{11}^{(i)} & \mathbf{K}_{12}^{(i)} & \mathbf{K}_{13}^{(i)} & \mathbf{K}_{14}^{(i)} \\
\mathbf{K}_{21}^{(i)} & \mathbf{K}_{22}^{(i)} & \mathbf{K}_{23}^{(i)} & \mathbf{K}_{24}^{(i)} \\
\mathbf{K}_{31}^{(i)} & \mathbf{K}_{32}^{(i)} & \mathbf{K}_{33}^{(i)} & \mathbf{K}_{34}^{(i)} \\
\mathbf{K}_{41}^{(i)} & \mathbf{K}_{42}^{(i)} & \mathbf{K}_{43}^{(i)} & \mathbf{K}_{44}^{(i)}
\end{array}\right],
$$

$$
\begin{aligned}
& \mathbf{e}^{(i)}=\left[e_{1}^{(i)} e_{2}^{(i)}\left|e_{3}^{(i)} e_{4}^{(i)}\right| e_{5}^{(i)} e_{6}^{(i)} \mid e_{7}^{(i)} e_{8}^{(i)}\right]^{T} \\
& =\left[\begin{array}{llll}
\mathbf{e}_{12}^{(i)} & \mathbf{e}_{34}^{(i)} & \mathbf{e}_{56}^{(i)} & \mathbf{e}_{78}^{(i)}
\end{array}\right]^{T},
\end{aligned}
$$$$
\mathbf{Q}^{(i)}=\left[\begin{array}{llll}
\mathbf{Q}_{12}^{(i)} & \mathbf{Q}_{34}^{(i)} & \mathbf{Q}_{56}^{(i)} & \mathbf{Q}_{78}^{(i)}
\end{array}\right]^{T}
$$

梁要素を結合した状態の運動方程式は以下の様に なる.

$$
\overline{\mathbf{M}} \ddot{\mathbf{e}}+\overline{\mathbf{K}} \overline{\mathbf{e}}=\overline{\mathbf{Q}} .
$$

ここで節点座標べクトル, 質量行列, 剛性行列, 外力ベ クトルは次のようになる。

$$
\overline{\mathbf{e}}=\left[\begin{array}{c}
\mathbf{e}_{12}^{(1)} \\
\mathbf{e}_{34}^{(1)} \\
\mathbf{e}_{56}^{(1)} \\
\mathbf{e}_{78}^{(1)} \\
\mathbf{e}_{56}^{(2)} \\
\mathbf{e}_{78}^{(2)}
\end{array}\right]=\left[\begin{array}{l}
\mathbf{e}_{12}^{(1)} \\
\mathbf{e}_{34}^{(1)} \\
\mathbf{e}_{12}^{(2)} \\
\mathbf{e}_{34}^{(2)} \\
\mathbf{e}_{56}^{(2)} \\
\mathbf{e}_{78}^{(2)}
\end{array}\right],
$$

$$
\overline{\mathbf{M}}=\left[\begin{array}{cccccc}
\mathbf{M}_{11}^{(1)} & \mathbf{M}_{12}^{(1)} & \mathbf{M}_{13}^{(1)} & \mathbf{M}_{14}^{(1)} & \mathbf{0} & \mathbf{0} \\
\mathbf{M}_{21}^{(1)} & \mathbf{M}_{22}^{(1)} & \mathbf{M}_{23}^{(1)} & \mathbf{M}_{24}^{(1)} & \mathbf{0} & \mathbf{0} \\
\mathbf{M}_{31}^{(1)} & \mathbf{M}_{32}^{(1)} & \mathbf{M}_{33}^{(1)}+\mathbf{M}_{11}^{(2)} & \mathbf{M}_{34}^{(1)}+\mathbf{M}_{12}^{(2)} & \mathbf{M}_{13}^{(2)} & \mathbf{M}_{14}^{(2)} \\
\mathbf{M}_{41}^{(1)} & \mathbf{M}_{42}^{(1)} & \mathbf{M}_{43}^{(1)}+\mathbf{M}_{21}^{(2)} & \mathbf{M}_{44}^{(1)}+\mathbf{M}_{22}^{(2)} & \mathbf{M}_{23}^{(2)} & \mathbf{M}_{24}^{(2)} \\
\mathbf{0} & \mathbf{0} & \mathbf{M}_{31}^{(2)} & \mathbf{M}_{32}^{(2)} & \mathbf{M}_{33}^{(2)} & \mathbf{M}_{34}^{(2)} \\
\mathbf{0} & \mathbf{0} & \mathbf{M}_{41}^{(2)} & \mathbf{M}_{42}^{(2)} & \mathbf{M}_{43}^{(2)} & \mathbf{M}_{44}^{(2)}
\end{array}\right]
$$

$$
\overrightarrow{\mathbf{K}}=\left[\begin{array}{cccccc}
\mathbf{K}_{11}^{(1)} & \mathbf{K}_{12}^{(1)} & \mathbf{K}_{13}^{(1)} & \mathbf{K}_{14}^{(1)} & \mathbf{0} & 0 \\
\mathbf{K}_{21}^{(1)} & \mathbf{K}_{22}^{(1)} & \mathbf{K}_{23}^{(1)} & \mathbf{K}_{24}^{(1)} & 0 & 0 \\
\mathbf{K}_{31}^{(1)} & \mathbf{K}_{32}^{(1)} & \mathbf{K}_{33}^{(1)}+\mathbf{K}_{11}^{(2)} & \mathbf{K}_{34}^{(1)}+\mathbf{K}_{12}^{(2)} & \mathbf{K}_{13}^{(2)} & \mathbf{K}_{14}^{(2)} \\
\mathbf{K}_{41}^{(1)} & \mathbf{K}_{42}^{(1)} & \mathbf{K}_{43}^{(1)}+\mathbf{K}_{21}^{(2)} & \mathbf{K}_{44}^{(1)}+\mathbf{K}_{22}^{(2)} & \mathbf{K}_{23}^{(2)} & \mathbf{K}_{24}^{(2)} \\
0 & 0 & \mathbf{K}_{31}^{(2)} & \mathbf{K}_{32}^{(2)} & \mathbf{K}_{33}^{(2)} & \mathbf{K}_{34}^{(2)} \\
0 & 0 & \mathbf{K}_{41}^{(2)} & \mathbf{K}_{42}^{(2)} & \mathbf{K}_{43}^{(2)} & \mathbf{K}_{44}^{(2)}
\end{array}\right]
$$

$$
\overline{\mathbf{Q}}=\left[\begin{array}{c}
\mathbf{Q}_{12}^{(1)} \\
\mathbf{Q}_{34}^{(1)} \\
\mathbf{Q}_{56}^{(1)}+\mathbf{Q}_{12}^{(2)} \\
\mathbf{Q}_{78}^{(1)}+\mathbf{Q}_{34}^{(2)} \\
\mathbf{Q}_{56}^{(2)} \\
\mathbf{Q}_{78}^{(2)}
\end{array}\right]
$$

3.2 任意角度での要秦の結合＼cjkstart図 3 に示すよう に2つの梁要素を任意の角度で固定し結合する場合に ついて考える. 梁要素を任意の角度で結合する場合, 直線的結合のようにそのまま質量行列, 剛性行列を重 ね合わせることはできない，それは，結合部分の節点 座標の勾配が点 $\mathrm{P}$ と点 $\mathrm{Q} て ゙$ 異なるからである，結合 点の $X Y$ 座標は同じとなるため,

$$
\mathbf{e}_{56}^{(1)}=\mathbf{e}_{12}^{(2)}
$$

という関係が成り立つ. 勾配を表す節点座標は軸歪と 角度を用いると以下のように表すことができる。

$$
\begin{aligned}
& e_{7}^{(1)}=\left(1+\varepsilon_{\mathrm{Q}}^{(1)}\right) \cos \theta_{1}, \\
& e_{8}^{(1)}=\left(1+\varepsilon_{\mathrm{Q}}^{(1)}\right) \sin \theta_{1}, \\
& e_{3}^{(2)}=\left(1+\varepsilon_{\mathrm{P}}^{(2)}\right) \cos \theta_{2}, \\
& e_{4}^{(2)}=\left(1+\varepsilon_{\mathrm{P}}^{(2)}\right) \sin \theta_{2} .
\end{aligned}
$$

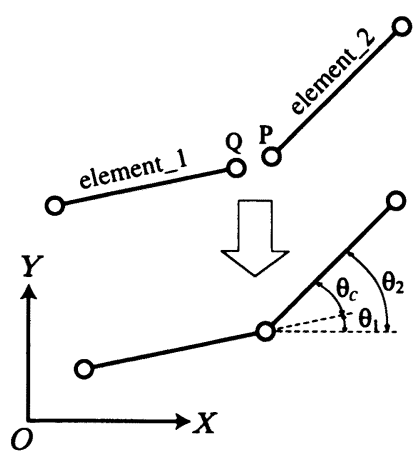

Fig. 3 Joint at corner part 
ここで, $\theta_{1}, \theta_{2}$ は図 3 に示す節点 $\mathrm{P}, \mathrm{Q}$ の角度であり， $\varepsilon_{\mathrm{Q}}^{(1)}, \varepsilon_{\mathrm{P}}^{(2)}$ は節点 $\mathrm{P}, \mathrm{Q}$ での軸歪を表す. 点 $\mathrm{P}$ の勾配を点 $\mathrm{Q}$ の勾配で表すことを考える. 三角関数の定理より次 式の関係が成り立つ。

$$
\begin{aligned}
e_{3}^{(2)} & =\left(1+\varepsilon_{\mathrm{P}}^{(2)}\right) \cos \left(\theta_{1}+\theta_{c}\right) \\
& =\left(1+\varepsilon_{\mathrm{P}}^{(2)}\right)\left(\cos \theta_{1} \cos \theta_{c}-\sin \theta_{1} \sin \theta_{c}\right), \\
e_{4}^{(2)} & =\left(1+\varepsilon_{\mathrm{P}}^{(2)}\right) \sin \left(\theta_{1}+\theta_{c}\right) \\
& =\left(1+\varepsilon_{\mathrm{P}}^{(2)}\right)\left(\sin \theta_{1} \cos \theta_{c}+\cos \theta_{1} \sin \theta_{c}\right) .
\end{aligned}
$$

ここで, $\theta_{c}$ は梁要素結合角度を表す定数である.この 式を行列で整理すると次式となる。

$$
\begin{aligned}
{\left[\begin{array}{l}
e_{3}^{(2)} \\
e_{4}^{(2)}
\end{array}\right] } & =\left(1+\varepsilon_{\mathrm{P}}^{(2)}\right)\left[\begin{array}{cc}
\cos \theta_{c} & -\sin \theta_{c} \\
\sin \theta_{c} & \cos \theta_{c}
\end{array}\right]\left[\begin{array}{l}
\cos \theta_{1} \\
\sin \theta_{1}
\end{array}\right] \\
& =\frac{1+\varepsilon_{\mathrm{P}}^{(2)}}{1+\varepsilon_{\mathrm{Q}}^{(1)}}\left[\begin{array}{cc}
\cos \theta_{c} & -\sin \theta_{c} \\
\sin \theta_{c} & \cos \theta_{c}
\end{array}\right]\left[\begin{array}{l}
e_{7}^{(1)} \\
e_{8}^{(1)}
\end{array}\right] .
\end{aligned}
$$

よって, 勾配を表す座標の座標变換行列は次式で表す ことができる。

$$
\mathbf{A}=\frac{1+\varepsilon_{\mathrm{P}}^{(2)}}{1+\varepsilon_{\mathrm{Q}}^{(1)}}\left[\begin{array}{cc}
\cos \theta_{c} & -\sin \theta_{c} \\
\sin \theta_{c} & \cos \theta_{c}
\end{array}\right] .
$$

このように，絶对節点座標で定式化された梁要素の座 標変換行列を厳密に導出すると, 梁要素の軸歪の影響 が含まれることが確認できた.ここでは実際の機械構 造物のモデル化を目標とし, 骨組棈造物の弾性变形範 囲内の解析を対象としている。このような問題では軸 歪は十分に微小であることから，座標変換行列を導出 するにあたり，次式のように近似ができると仮定する.

$$
\frac{1+\varepsilon_{\mathrm{P}}^{(2)}}{1+\varepsilon_{\mathrm{Q}}^{(1)}}=1 .
$$

これにより,梁要素 2 を梁要素 1 に任意角度で結合す る場合の節点座標全体の变換行列は次式で表すことが できる.

$$
\mathbf{A}=\left[\begin{array}{cccccccc}
1 & 0 & 0 & 0 & 0 & 0 & 0 & 0 \\
0 & 1 & 0 & 0 & 0 & 0 & 0 & 0 \\
0 & 0 & \cos \theta_{c} & -\sin \theta_{c} & 0 & 0 & 0 & 0 \\
0 & 0 & \sin \theta_{c} & \cos \theta_{c} & 0 & 0 & 0 & 0 \\
0 & 0 & 0 & 0 & 1 & 0 & 0 & 0 \\
0 & 0 & 0 & 0 & 0 & 1 & 0 & 0 \\
0 & 0 & 0 & 0 & 0 & 0 & 1 & 0 \\
0 & 0 & 0 & 0 & 0 & 0 & 0 & 1
\end{array}\right] .
$$

梁要素の結合角度 $\theta_{c}$ は定数であるから, 梁要素の運動 状態にかかわらず，この座標変換行列は定数行列であ
る.この座標変換行列を用いることにより，梁要素を 結合した状態の運動方程式は次式で表すことができる。

$$
\overline{\mathbf{M}} \ddot{\mathbf{e}}+\overline{\mathbf{K}} \overline{\mathbf{e}}=\overline{\mathbf{Q}} .
$$

ここで, 質量行列, 剛性行列, 節点座標ベクトル, 外力 ベクトルは以下のとおりである。

$$
\begin{gathered}
\overline{\mathbf{e}}=\left[\mathbf{e}_{12}^{(1)}, \mathbf{e}_{34}^{(1)}, \mathbf{e}_{56}^{(1)}, \mathbf{e}_{78}^{(1)}, \mathbf{e}_{56}^{(2)}, \mathbf{e}_{78}^{(2)}\right]^{T} \\
\overline{\mathbf{M}}=\left[\begin{array}{cccccc}
\mathbf{M}_{11}^{(1)} & \mathbf{M}_{12}^{(1)} & \mathbf{M}_{13}^{(1)} & \mathbf{M}_{14}^{(1)} & \mathbf{0} & \mathbf{0} \\
\mathbf{M}_{21}^{(1)} & \mathbf{M}_{22}^{(1)} & \mathbf{M}_{23}^{(1)} & \mathbf{M}_{24}^{(1)} & \mathbf{0} & \mathbf{0} \\
\mathbf{M}_{31}^{(1)} & \mathbf{M}_{32}^{(1)} & \mathbf{M}_{33}^{(1)}+\hat{\mathbf{M}}_{11}^{(2)} & \mathbf{M}_{34}^{(1)}+\hat{\mathbf{M}}_{12}^{(2)} & \hat{\mathbf{M}}_{13}^{(2)} & \hat{\mathbf{M}}_{14}^{(2)} \\
\mathbf{M}_{41}^{(1)} & \mathbf{M}_{42}^{(1)} & \mathbf{M}_{43}^{(1)}+\hat{\mathbf{M}}_{21}^{(2)} & \mathbf{M}_{44}^{(1)}+\hat{\mathbf{M}}_{22}^{(2)} & \hat{\mathbf{M}}_{23}^{(2)} & \hat{\mathbf{M}}_{24}^{(2)} \\
\mathbf{0} & \mathbf{0} & \hat{\mathbf{M}}_{31}^{(2)} & \hat{\mathbf{M}}_{32}^{(2)} & \hat{\mathbf{M}}_{33}^{(2)} & \hat{\mathbf{M}}_{34}^{(2)} \\
\mathbf{0} & \mathbf{0} & \hat{\mathbf{M}}_{41}^{(2)} & \hat{\mathbf{M}}_{42}^{(2)} & \hat{\mathbf{M}}_{43}^{(2)} & \hat{\mathbf{M}}_{44}^{(2)}
\end{array}\right],
\end{gathered}
$$$$
\overline{\mathbf{K}}=\left[\begin{array}{cccccc}
\mathbf{K}_{11}^{(1)} & \mathbf{K}_{12}^{(1)} & \mathbf{K}_{13}^{(1)} & \mathbf{K}_{14}^{(1)} & \mathbf{0} & \mathbf{0} \\
\mathbf{K}_{21}^{(1)} & \mathbf{K}_{22}^{(1)} & \mathbf{K}_{23}^{(1)} & \mathbf{K}_{24}^{(1)} & \mathbf{0} & \mathbf{0} \\
\mathbf{K}_{31}^{(1)} & \mathbf{K}_{32}^{(1)} & \mathbf{K}_{33}^{(1)}+\hat{\mathbf{K}}_{11}^{(2)} & \mathbf{K}_{34}^{(1)}+\hat{\mathbf{K}}_{12}^{(2)} & \hat{\mathbf{K}}_{13}^{(2)} & \hat{\mathbf{K}}_{14}^{(2)} \\
\mathbf{K}_{41}^{(1)} & \mathbf{K}_{42}^{(1)} & \mathbf{K}_{43}^{(1)}+\hat{\mathbf{K}}_{21}^{(2)} & \mathbf{K}_{44}^{(1)}+\hat{\mathbf{K}}_{22}^{(2)} & \hat{\mathbf{K}}_{23}^{(2)} & \hat{\mathbf{K}}_{24}^{(2)} \\
\mathbf{0} & \mathbf{0} & \hat{\mathbf{K}}_{31}^{(2)} & \hat{\mathbf{K}}_{32}^{(2)} & \hat{\mathbf{K}}_{33}^{(2)} & \hat{\mathbf{K}}_{34}^{(2)} \\
\mathbf{0} & \mathbf{0} & \hat{\mathbf{K}}_{41}^{(2)} & \hat{\mathbf{K}}_{42}^{(2)} & \hat{\mathbf{K}}_{43}^{(2)} & \hat{\mathbf{K}}_{44}^{(2)}
\end{array}\right]
$$

$$
\begin{gathered}
\overline{\mathbf{Q}}=\left[\begin{array}{c}
\mathbf{Q}_{12}^{(1)} \\
\mathbf{Q}_{34}^{(1)} \\
\mathbf{Q}_{56}^{(1)}+\hat{\mathbf{Q}}_{12}^{(2)} \\
\mathbf{Q}_{78}^{(1)}+\hat{\mathbf{Q}}_{34}^{(2)} \\
\hat{\mathbf{Q}}_{56}^{(2)} \\
\hat{\mathbf{Q}}_{78}^{(2)}
\end{array}\right] \\
\hat{\mathbf{M}}^{(2)}=\mathbf{A}^{T} \mathbf{M}^{(2)} \mathbf{A}, \\
\hat{\mathbf{K}}^{(2)}=\mathbf{A}^{T} \mathbf{K}^{(2)} \mathbf{A}, \\
\hat{\mathbf{Q}}^{(2)}=\mathbf{A}^{T} \mathbf{Q}^{(2)}
\end{gathered}
$$

さらに, 要素 2 の別の節点に新たな要素 3 を任意角 度で結合する場合には, 要素 1 と要素 2 の場合と同様 に結合角度を設定することで, 要素 3 の結合部分の節 点座標を要素 2 の節点座標で表すための座標変換行列 を導出することができる.この座標変換行列を要素 3 の質量行列, 剛性行列, 外力ベクトルに作用させ, 要素 2 の結合部分の節点に対応する行列に重ね合わせるこ とで結合後の運動方程式を導くことができる. 
複数の梁要素が 1 つの節点において任意角度で結合 される場合には, 基準となる一つの梁要素を考える. 基 準要素から各要素の結合角度を定義することで, 各要 素の結合部分の節点座標を基準要素の節点座標で表す ための座標変換行列を導出することができる. 各要素 に対する座標変換行列を各要素の質量行列, 剛性行列, 外カベクトルに作用させ, 基準要素の結合部分の節点 に対応する行列に重ね合わせることで, 結合後の運動 方程式を導くことができる.

このようにして, 絶対節点座標で定式化された複数 の梁要素を, 行列の重极合わせにより任意の角度で結 合し, 骨組構造物をモデル化することが可能となった. 軸歪が微小な範囲に解析を限定し, 厳密には座標変換 行列に含まれる軸歪の影響を消去することで絶対節点 座標用の座標変換行列を式(38)のように導出したこと が本論文の特徵である. 絶対節点座標アプローチによ る定式化においてこのような座標変換行列を用いてい る論文は見当たらない.これにより線形有限要素法と 同じように行列の重ね合わせで梁要素の結合処理がで き, 結合後の運動方程式は常微分方程式で表すことが できる. 拘束式を用いた微分代数方程式として処理す る必要がなく, 梁要素の結合処理が容易となった。 ま た,この座標変換行列は時間によって変化しない定数 行列であるため, 大变位 ·大回転問題においても骨組 構造物の質量行列と曲げ剛性行列は定数行列として記 述できる.

\section{4. 数値計算による検証}

4 .1 静的問題による検証提案した手法を検証 するために静的問題を解析し, 線形有限要素法と比較 検討を行った. 図 4 に解析モデルを示す. 同じ長さの梁 を直角に結合し, 先端にトルクを加える.ここでは, 梁 の長さ $L=1 \mathrm{~m}$, 縦弾性係数 $E=210 \mathrm{GPa}$, 梁の断面は 半径 $5 \mathrm{~cm}$ の円形状とした. 線形変形範囲内で比較する ため外カトルク $T$ は小さい值とし $T L / E I=0.0005$ となるように設定した. 長さ $L$ の梁を $5 つ に$ 要素分割 し、ニュートン法により収束計算を行った，計算する にあたり，両手法とも市販ソフトのMATLABを用い て解析ソフトを開発した. 絶対節点座標アプローチに よる骨組みモデルでは, 梁の軸方向の変形に対する剛 性行列に節点座標が含まれる. 収束計算を行うにあた $\eta, n+1$ ステップの解を求めるのに $n$ ステップの状 態の節点座標を用いて剛性行列を近似した。

静的に釣合った状態の全体座標系から見た $\mathrm{P}$ 点の座 標を表 1 に示す. 線形有限要素法 (FEM) による骨組
Table 1 Simulation result at node $\mathrm{P}$

\begin{tabular}{|c|c|c|}
\hline Coordinate & FEM approach & ANC approach \\
\hline$X[\mathrm{~m}]$ & 1.00025 & 1.000249 \\
\hline$Y[\mathrm{~m}]$ & 0.99925 & 0.999249 \\
\hline$\theta[\mathrm{rad}]$ & -0.001 & -0.00099 \\
\hline
\end{tabular}

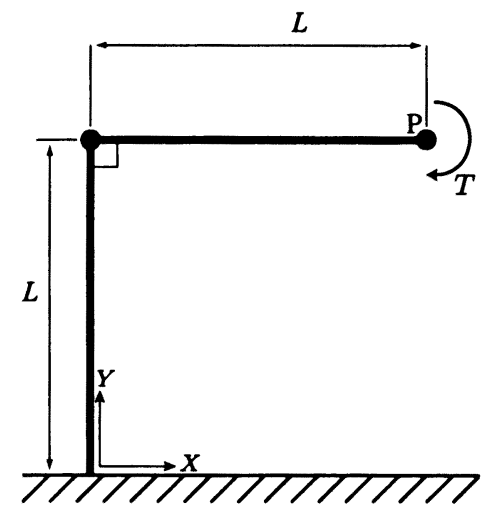

Fig. 4 Analysis model for static problem

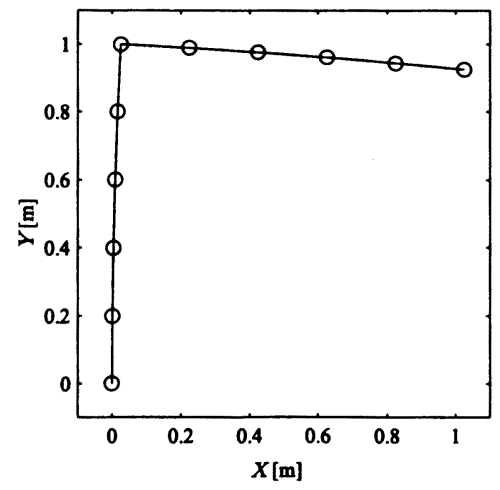

(a) FEM approach

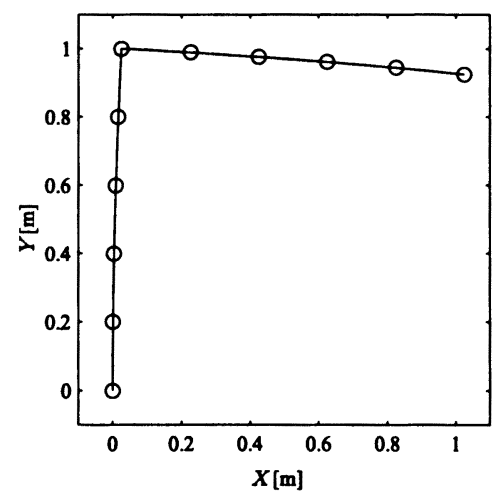

(b) ANC approach

Fig. 5 Comparison of simulation results 


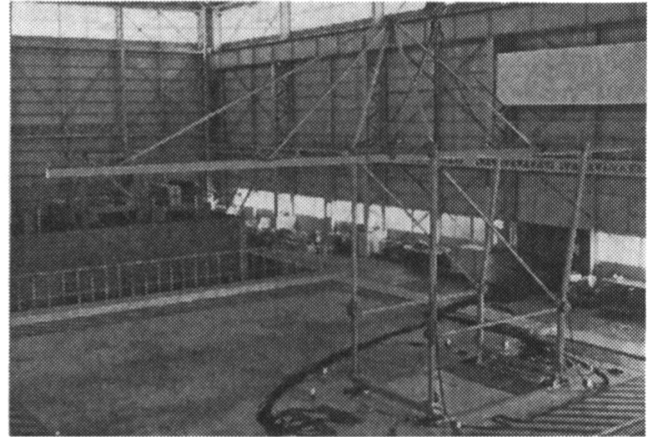

Fig. 6 Experiment of crane model (1/8 scale)

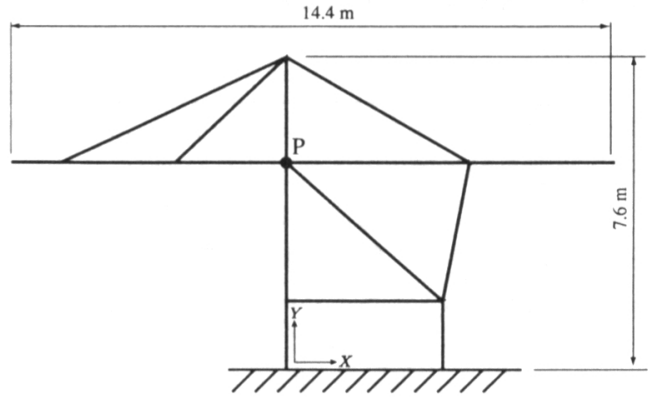

Fig. 7 Simulation model of crane

みモデルと，提案した絶対節点座標 $(\mathrm{ANC})$ アプロー チによる骨組みモデルの解析結果が一致していること が確認できる. 図 5 では解析結果を比較しやすいよう に, 初期状態からの変形量を 100 倍にして変形状態を 表している. 両骨組みモデルの変形状態は良く一致し ており, 微小変形範囲において提案した結合方法が静 的問題に有効であることが確認できた。

4.2 振動問題への適用 (クレーンモデル) 次に 動的問題への適用を検討する。図 6 と図 7 は港湾に設 置されているコンテナクレーンの $1 / 8$ スケールモデル を表している. 1997 年にこの 1/8 スケールモデルを 用いたコンテナクレーン振動実験が行われており，コ ンテナクレーンのモデル化や耐震性評価に関する研究 が既に報告されている(13) (14).ここでは提案手法によ り骨組み構造モデルを作成し，振動実験との比較検証 を行った。

図 8 に実験結果とシミュレーション結果を示す。実 験には 1968 年に発生した北海道十勝沖地震の八戸港 湾で計測されたNS 方向の波形を用いた。図 8(a) は 実験に用いた $X$ 軸方向の地震波形を示している。最 大加速度は $1.69 \mathrm{~m} / \mathrm{s}^{2}$ とし, 相似則により地震波形の 時間軸を $1 / \sqrt{8}$ 倍にしている。(b) は実験によって得

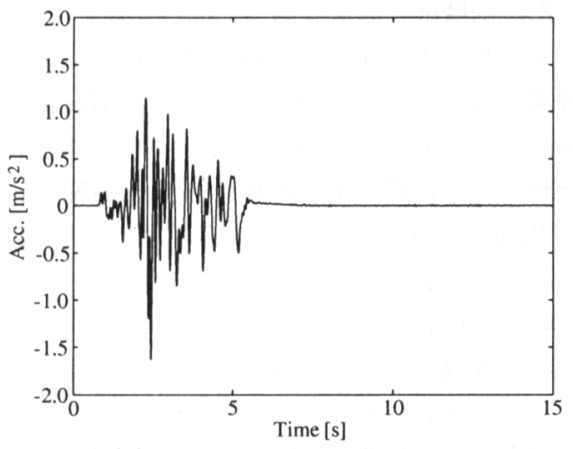

(a) Input earthquake wave

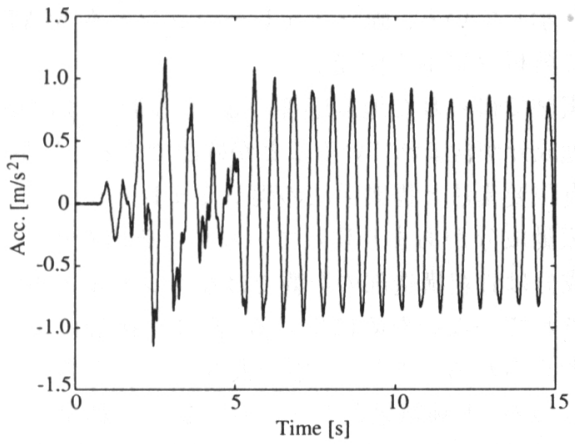

(b) Experimental result at node $\mathrm{P}$

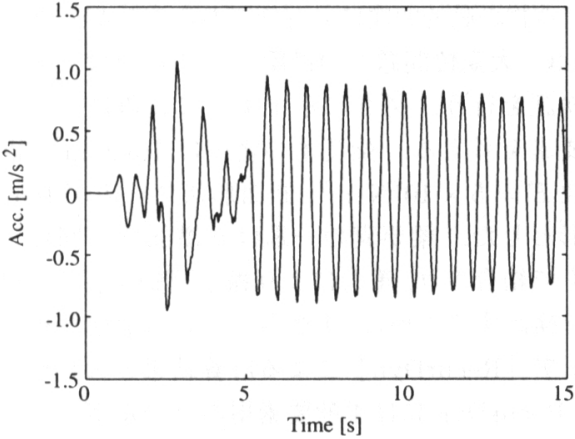

(c) Simulation result (FEM)

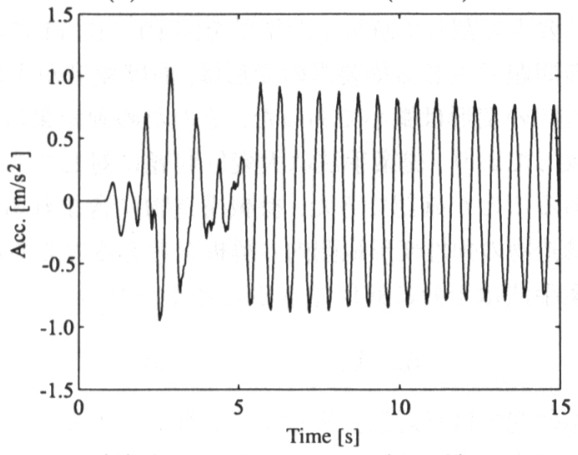

(d) Simulation result (ANC)

Fig. 8 Comparison of results 
られた時刻暦応答波形であり, 図 7 に示すコンテナク レーンの P 点の加速度 $(X$ 軸方向) を示している.こ の地震応答より 1 次固有振動数は $1.65 \mathrm{~Hz}, 1$ 次モー ド隇衰比は $0.18 \%$ と同定することができた。これよ り解析モデルに導入する隇衰行列 $\mathbf{C}=\alpha \mathbf{M}$ の係数を $\alpha=2 \zeta_{1} \omega_{1}=0.0373$ とした. また, レールと車輪部 は浮き上がり挙動がほとんど観測されなかったことか ら, ピンジョイント結合でモデル化を行った. (c) は従 来の線形有限要素法 (FEM) によるシミュレーション 結果であり，(d) は絶対節点座標 (ANC) で定式化され た梁要素を用いた提案手法によるシミュレーション結 果を示している. 両シミュレーションとも MATLAB にて解析ソフトを開発した.

実験で得られた地震応答の $3 \sim 5$ 秒間には約 $6 \mathrm{~Hz}$ の 振動成分が含まれていることが確認できる.しかし, 線 形有限要素法と提案手法の両シミュレーションではこ の振動成分があまり現れていない. そのため, この振 動成分は骨組構造部の影響ではなくレールと車輪が結 合されていないために生じる, 滑りや接触による影響 と考えられる. また，振幅の大きさに若干の違いがあ るものの, 実験結果とシミュレーション結果の全体的 な地震応答の挙動は良く一致しており, 提案手法が骨 組構造物の動的問題にも有効であることが確認できた.

4.3 大変位問題への適用 ここでは大変位問題 で検証を行う。図 9 に示すように直角に結合された 梁要素を考える. 梁要素の密度は $10 \mathrm{~kg} / \mathrm{m}^{3}$; 絴弾性 係数 $E=5 \times 10^{8} \mathrm{~N} / \mathrm{m}^{2}$, 断面形状は一辺が $1 \mathrm{~cm}$ の正 方形とした。梁要素の一端は基礎部分に回転ジョイ ントで結合され, 重力により振子運動を行う. 提案手 法を検証するために, 市販されている機構解析ソフト ウェア「RecurDyn」による計算結果との比較を行っ た. RecurDynには柔軟要素用のツールボックスが用 意されており，その中の梁要素でモデル化を行った. 6 つに要素分割して解析した結果を図 10 と図 11 に示す. この問題で生じる梁要素の変形は, 曲げ変形が主体で, 軸方向の変形は微小であった，そのため両結果は良く 一致しており，提案手法は大变位問題に対しても有効 であることが確認できた。機械構造物に含まれる骨組 み構造物の弾性変形範囲内の解析を考えるのであれば, 提案手法は十分に適用できると考えられる.

\section{5. 結言}

本研究では絶対節点座標で定式化された梁要素を用 いた場合の骨組構造モデル作成方法を提案した。この 梁要素は節点座標に角度を用いずに勾配を用いている. そのため線形有限要素法の座標変換行列を用い, 行列

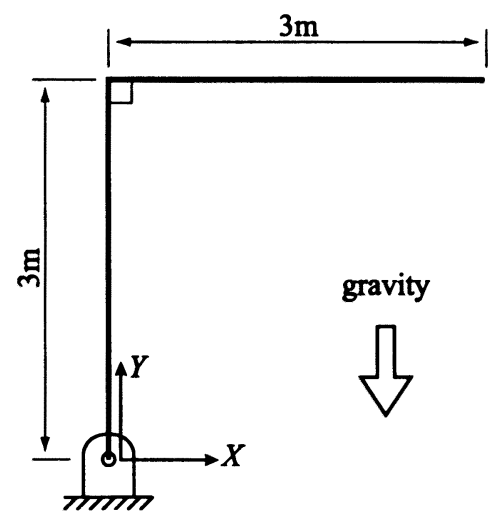

Fig. 9 Analysis model for large displacement problem

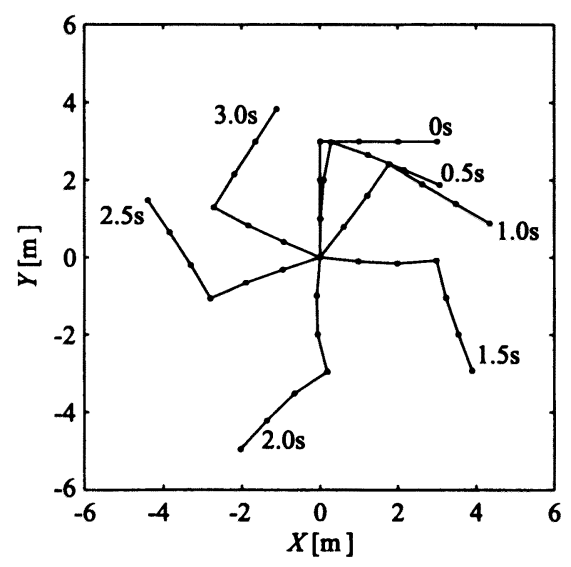

Fig. 10 Simulation result (RecurDyn)

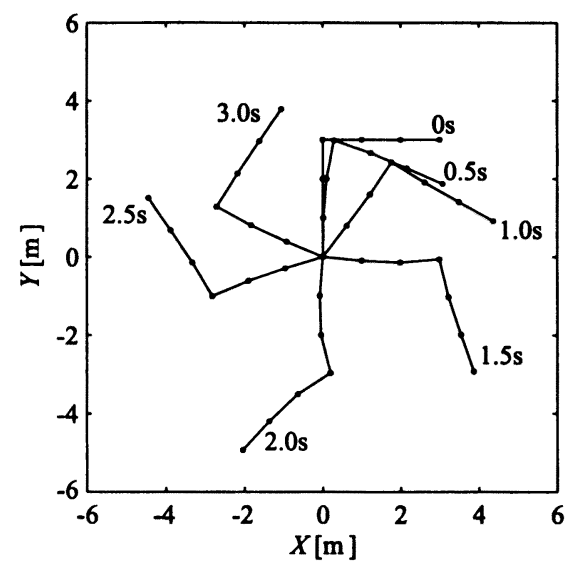

Fig. 11 Simulation result (proposed method) 
の重ね合わせで梁要素を結合することはできない. 拘 束条件式を用いてマルチボディダイナミクスの手法を 用いて結合することもできるが，モデル全体の運動方 程式は微分代数方程式となる. 本論文ではこの梁要素 用の座標変換行列を導出し, 行列の重ね合わせで梁要 素を結合する方法を提案した. 提案手法では梁要素の 結合後の運動方程式は微分代数方程式でなく常微分方 程式で表わされる．また，大变位問題であっても質量 行列, 曲げ剛性行列は定数行列として記述することが できる。

提案手法を検証するために, 静的問題を線形有限要 素法と比較検討を行った. 微小変形範囲内において, 提 案手法の計算結果は線形有限要素法と良く一致してお り, 提案手法が静的問題において有効であることが確 認できた。また，動的問題に対してはコンテナクレー ンを対象に，振動加振実験結果と解析結果の比較検討 を行った. 実験結果と提案手法の解析結果は良く一致 しており，本手法が動的問題においても有効であるこ とが実験により確認することができた. 大変位問題に 対しても沉用機構解析ソフトウェアによる解析結果と 一致していることから, 提案手法が有効であることが 確認できた. 絶対節点座標で定式化された梁要素の座 標変換行列は, 嚴密には軸歪の影響を受けるが, 実際 の骨組構造物の弾性変形範囲内の解析であれば，この 影響を省略した座標变換行列でも十分に利用できるこ とがシミュレーションにより確認できたことになる.

本手法を用いれば剛体運動を有する骨組構造モデル の運動解析にも，そのまま適用できる。そそのため，ク レーンの転倒挙動や, 大型振動台による大変位加振を 想定したシミュレーション, 液状化による地瞥の移動 に対する䭱造物の挙動解析への応用も考えられる.

\section{文献}

(1) B.F.De Veubeke, The Dynamics of Flexible Bodies, International Journal for Engineering Science, 14, (1976), 895-913.

(2) R.L.Huston, Multi-body Dynamics Including the Effect of Flexibility and Compliance, Computer and Structures, 14, (1981), 443-451.

(3) R.L.Huston, Computer Methods in Flexible Multibody Dynamics, International Journal for Numerical Methods in Engineering, 32, (1991), 1657-1668.

(4) J.C.Simo and L.Vu-Quoc, On the Dynamics of Flexible Beams under Large Overall Motions - The
Plane Case: Parts I and II, ASME Journal of Applied Mechanics, 53, (1986), 849-863.

(5) M.Iura and S.N.Atluri, Dynamic Analysis of Planar Flexible Beams with Finite Rotations by using Inertial and Rotating Frames, Computers \& Structures, 55-3, (1995), 453-462.

(6) 本家, 井上, ほか 2 名, 柔軟リンク構造物のシミュ レーションに関する研究（大变位運動を考慮した 低次元化手法と大変位 2 節点要素の開発)，機論， 64-620, C(1998), 1176-1183.

(7) A.A.Shabana, An Absolute Nodal Coordinate Formulation for the Large Rotation and Deformation Analysis of Flexible Bodies, Technical Report \#MBS96-1-UIC, Department of Mechanical Engineering,University of Illinois at Chicago, (1996).

(8) A.A.Shabana, H.A.Hussien and J.L.Escalona, Application of the Absolute Nodal Coordinate Formulation to Large Rotation and Large Deformation Problems, ASME Journal of Mechanical Design, 120, (1998), 188-195.

(9) Y.Takahashi and N.Shimizu, Study on Elastic Forces of the Absolute Nodal Coordinate Formulation for Deformable Beams, ASME Proceedings of Design Engineering Technical Conferences, (1999), VIB-8203.

（10）高橋, 清水, Absolute Nodal Coordinate 法による 梁の多体動力学解析に関する研究 (有限変位·微小歪 とした時の弾性力の導出)，機論, 67-655, C(2001), 626-632.

(11) 高橋, 清水, 鈴木, 絶対節点座標アプローチによ り定式化された柔軟マルチボディダイナミクスにお ける梁要素の隇衰行列に関する研究, 機論, 69-685, C(2003), 2225-2232.

(12) 生田, 曄道, 須田, 移動質量を伴うフレキシブル . マルチボディ・ダイナミクスの基礎的研究, 日本機械 学会, 機械力学・計測制御講演論文集 (Vol.A), 99-7, (1999), 205-208.

(13) 金山, 柏崎, 大地震時におけるコンテナクレーン の脚の浮き上がり挙動評価, 機論, 64-618, C(1998), 480-486.

(14) 栗原, 小林, 複雑な形状を有する物体の接触問題へ の一つのアプローチ, 機論, 66-646, C(2000), 18161822. 